\title{
Osteoprotegerin Expression in Liver is Induced by IL13 through TGF $\beta$
}

\author{
Adhyatmika Adhyatmika a,b Kurnia S. S. Putric,d Emilia Gorec Keri A. Mangnus ${ }^{a}$ \\ Catharina Reker-Smit ${ }^{a}$ Detlef Schuppan ${ }^{\text {ef }}$ Leonie Beljaars ${ }^{c}$ Peter Olinga ${ }^{c}$ \\ Barbro N. Melgertg,h
}

aDepartment of Pharmacokinetics, Toxicology, and Targeting, Groningen Research Institute of Pharmacy, University of Groningen, Groningen, The Netherlands, 'bepartment of Pharmaceutics, Faculty of Pharmacy, Universitas Gadjah Mada, Yogyakarta, Indonesia, 'Department of Pharmaceutical Technology and Biopharmacy, Groningen Research Institute of Pharmacy, University of Groningen, Groningen, The Netherlands, 'Faculty of Pharmacy, Universitas Indonesia, Depok, West Java, Indonesia, eInstitute of Translational Immunology, University Medical Center of the Johannes Gutenberg University Mainz, Mainz, Germany, 'Division of Gastroenterology, Beth Israel Deaconess Medical Center, Harvard Medical School, Boston, MA, USA, 'Department of Molecular Pharmacology, Groningen Research Institute of Pharmacy, University of Groningen, Groningen, The Netherlands, hGroningen Research Institute for Asthma and COPD, University Medical Center Groningen, Groningen, The Netherlands

\section{Key Words}

Fibrosis $\cdot$ Fibroblast $\cdot \mathrm{STAT}-6 \cdot \mathrm{AP}-1 \cdot \mathrm{IL} 13$ receptor

\begin{abstract}
Background/Aims: Osteoprotegerin (OPG) is a profibrotic mediator produced by myofibroblasts under influence of transforming growth factor $\beta$ (TGF $\beta$ ). Its expression in experimental models of liver fibrosis correlates well with disease severity and treatment responses. The regulation of OPG in liver tissue is largely unknown and we therefore set out to elucidate which growth factors/interleukins associated with fibrosis induce OPG and through which pathways. Methods: Precision-cut liver slices of wild type and STAT6-deficient mice and 3T3 fibroblasts were used to investigate the effects of TGF $\beta$, interleukin (IL) 13 (IL13), IL1 $\beta$, and platelet-derived growth factor BB (PDGF-BB) on expression of OPG. OPG protein was measure by ELISA, whereas OPG mRNA and expression of other relevant genes was measured by $q P C R$. Results: In addition to TGF $\beta$, only IL13 and not PDGF-BB or IL1 $\beta$ could induce OPG expression in 3 T3 fibroblasts and liver slices. This IL13-dependent induction was not shown in liver slices of STAT6-deficient mice and when wild type slices were cotreated with TGF $\beta$ receptor 1 kinase inhibitor galunisertib, STAT6 inhibitor AS1517499, or AP1 inhibitor T5224. This suggests that the OPG-inducing effect of IL13 is mediated through IL13 receptor $\alpha 1$-activation and subsequent STAT6-dependent upregulation of IL13 receptor $\alpha 2$, which in turn activates AP1 and induces production of TGF $\beta$ and subsequent production of OPG. Conclusion: We have
\end{abstract}




\section{Cellular Physiology Cell Physiol Biochem 2022;56:28-38 \\ \begin{tabular}{ll|l} 
and Biochemistry & $\begin{array}{l}\text { DOI: 10.33594/000000492 } \\
\text { Published online: } 22 \text { January } 2022\end{array}$ & $\begin{array}{l}\text { C } 2022 \text { The Author(s). Published by } \\
\text { Cell Physiol Biochem Press GmbH\&Co. KG }\end{array}$ \\
\hline
\end{tabular} \\ Adhyatmika et al.: Liver OPG is Induced by IL13}

shown that IL13 induces OPG release by liver tissue through a TGF $\beta$-dependent pathway involving both the $\alpha 1$ and the $\alpha 2$ receptor of IL13 and transcription factors STAT6 and AP1. OPG may therefore be a novel target for the treatment liver fibrosis as it is mechanistically linked to two important regulators of fibrosis in liver, namely IL13 and TGF $\beta 1$.

(C) 2022 The Author(s). Published by

Cell Physiol Biochem Press GmbH\&Co. KG

\section{Introduction}

Liver fibrosis is a chronic disease induced by long term injury and/or inflammation initiated by virus infections or chemical-induced injury, for example drugs or alcohol [1]. The main pathological characteristic of liver fibrosis is persistent extracellular matrix formation by hepatic stellate cells, which in turn prevents the regrowth of functional hepatocytes [2]. The disease has a high burden as there is no possible therapy to reverse the process when it has fully developed and therefore transplantation is the only option [3].

Transforming growth factor $\beta$ (TGF $\beta$ ) has been widely studied for many years as one of the central players in liver fibrosis, but this has not yielded any effective new drugs yet $[4,5]$. It is therefore likely that the process of fibrosis development is far more complicated than just the actions of TGF $\beta$ alone and that we need to understand the different players and interactions better to develop potential drug candidates.

We recently became interested in the actions of osteoprotegerin $(\mathrm{OPG}$, gene name TNFRSF11B) after finding that OPG is produced in high quantities by (liver) fibroblasts, especially after stimulation with TGF $\beta$ and that OPG itself can induce expression of TGF $\beta$, indicating a feed-forward loop [6]. Several clinical studies have shown that higher serum levels of OPG are associated with having liver fibrosis/cirrhosis [7-13]. In addition, OPG serum levels are part of a novel diagnostic score called Coopscore ${ }^{\circledR}$ that has better diagnostic performance than Fibrometer $\AA$, Fibrotest $\AA$, Hepascore $\AA$ and Fibroscan $^{T M}$ in chronic hepatitis C-associated fibrosis [8]. Moreover, in our previous studies, we have demonstrated high hepatic OPG production in liver tissue of patients transplanted for liver cirrhosis and in murine models of liver fibrosis.

Osteoprotegerin is well known for its role in protecting bone matrix degradation [14], but little is known about its function in nonbone tissues. In that respect, its role in vascular calcifications is probably best studied, showing that OPG protects against vascular calcification [15]. This contrasts with its known functional influence in bone metabolism in which it induces calcification of bone [14]. This suggests that OPG has more possible functions unrelated to bone and our previous data show its firm associations with fibrotic processes and TGF $\beta$ signaling in (myofibroblasts) [6]. However, little is known about the regulation of OPG production in (liver) fibroblasts by other mediators involved in fibrosis [16]. In this study we therefore aimed to further investigate OPG regulation in the liver by studying the effects of several key fibrosis-related growth factors/interleukins and their downstream signaling pathways. These were interleukin (IL) $1 \beta$ representing a pro-inflammatory and profibrotic mediator, platelet-derived growth factor BB (PDGF-BB), and IL13, both wellknown pro-fibrotic mediators for early and late fibrosis respectively.

\section{Materials and Methods}

\section{Animals}

Male and female wild-type C57BL/6 mice were obtained from Harlan (Horst, The Netherlands) and male STAT6(-/-) C57BL/6 mice were bred in the Institute of Translational Immunology, University Medical Center of the Johannes Gutenberg University Mainz, Germany [17]. Animals were kept in cages with a 12 hour of light/dark cycle and received food and water ad libitum. The use of C57BL/6 mice in this study was approved by the Institutional Animal Care and Use Committee of the University of Groningen (DEC 6416 AA) and the use of STAT6(-/-) mice by the Institutional Animal Care and Use Committee of the Government of Rhineland Palatinate under the reference number 2317707/G12-1-007. 


\section{Cellular Physiology Cell Physiol Biochem 2022;56:28-38 \\ \begin{tabular}{l|l}
\hline DOI: 10.33594/000000492 & C 2022 The Author(s). Published by
\end{tabular} \\ Published online: 22 January 2022 Cell Physiol Biochem Press GmbH\&Co. KG \\ Adhyatmika et al.: Liver OPG is Induced by IL13}

\section{Precision-cut liver slices}

Murine precision-cut liver slices were prepared as described before by De Graaf et al. [18]. Slices were treated with $5 \mathrm{ng} / \mathrm{mL}$ TGF $\beta$ (Peprotech, Rocky Hill, US), 10 ng/mL IL13 (Peprotech), $10 \mathrm{ng} / \mathrm{mL}$ IL1 $\beta$ (Peprotech), 10 ng/mL PDGF-BB (Peprotech), 10 mM galunisertib (Selleckchem, Munich, Germany), $21 \mathrm{nM}$ AS1517499 (Axon MedChem, Groningen, The Netherlands), and/or $10 \mu \mathrm{M}$ T5224 (ApexBio, Houston, US) in triplicate for a total of 48 hours and culture medium was refreshed every 24 hours.

\section{In vitro cell lines}

50,000/well 3T3 murine fibroblasts (The American Type Culture Collection, ATCC® CRL-1658) were cultured in standard medium of Gibco® Dulbecco's Modified Eagle Medium (Thermo Scientific, Waltham, Massachussets, US) containing 4.5 g/L D-Glucose (Sigma-Aldrich, Missouri, US), 2 mM L-Glutamine (Thermo Scientific, Waltham, Massachussets, US), and 10\% of fetal calf serum (Biowest, Nuaillé, France). Cells were starved with medium containing $0.5 \%$ serum 24 hours prior to other treatments. Treatments with TGF $\beta$, IL13, IL1 $\beta$, and PDGF-BB were done at similar concentrations as described for the experiments with slices.

\section{Generation of tissue lysate}

Tissue slices were lysed with extraction buffer containing $25 \mathrm{mM}$ Tris (Sigma-Aldrich, Missouri, US), $10 \mathrm{mM}$ sodium phosphate (Sigma-Aldrich), $150 \mathrm{mM} \mathrm{NaCl}$ (Sigma-Aldrich, Missouri, US), 0.1\% SDS (SigmaAldrich, Missouri, US), 1\% Triton-X 100 (Sigma-Aldrich, Missouri, US), and protease inhibitor (Thermo Scientific, Waltham, Massachussets, US) and incubated for 5 minutes at room temperature before snapfreezing and stored at $-80^{\circ} \mathrm{C}$ until analysis.

\section{Osteoprotegerin analysis}

Osteoprotegerin was measured in culture supernatants of cells and slices using a murine OPG DuoSet ${ }^{\circledR}$ ELISA kit (R\&D Systems, Minneapolis, US) according to the instructions provided by the manufacturer.

\section{Messenger RNA analysis}

Messenger RNA was isolated from cells or slices (three slices per sample, pooled, homogenized prior to extraction) using Maxwell@ LEV Simply RNA Cells/Tissue kit (Promega, Madison, Wisconsin, US). A NanoDrop® ND-1000 Spectrophotometer (Thermo Scientific) was used to measure total mRNA concentration in samples. cDNA synthesis from the mRNA was performed using a Moloney Murine Leukemia Virus Reverse Transcriptase (M-MLV RT) kit (Promega, Madison, Wisconsin, USA) in a Mastercycler® Gradient (Eppendorf, Hamburg, Germany) programmed for 10 minutes at $20^{\circ} \mathrm{C}, 30$ minutes at $42^{\circ} \mathrm{C}, 12$ minutes at $20^{\circ} \mathrm{C}, 5$ minutes at $990 \mathrm{C}$, and 5 minutes at $20^{\circ} \mathrm{C}$. Transforming growth factor beta 1 (TGF $\beta 1$ ), IL13 receptor $\alpha 2$ (IL13R $\alpha 2$ ), pro-collagen 1 subunit $\alpha 1$ (Col1 $\alpha 1)$, $\alpha$-smooth muscle actin ( $\alpha$ SMA), heat shock protein 47 (HSP47), plasminogen activator inhibitor 1 (PAI1), and fibronectin 1 (Fn1) genes were quantified using quantitative real time PCR (RT qPCR) from the synthesized cDNA, using SensiMixTM SYBR® Green (Bioline, London, UK) in a 7900HT Real-Time PCR sequence detection system (Applied Biosystems, Waltham, Massachussets, US) with primer sequences as presented in Table 1. PCR analysis consisted of 45 cycles of 10 min at $95^{\circ} \mathrm{C}, 15$ seconds at $95^{\circ} \mathrm{C}$, and 25 seconds at $60^{\circ} \mathrm{C}$ (repeated for 40 times) followed by a dissociation stage of $95^{\circ} \mathrm{C}$ for 15 seconds, $60^{\circ} \mathrm{C}$ for 15 seconds, and $95^{\circ} \mathrm{C}$ for 15 seconds. Output data were analyzed using SDS 2.4 software (Applied Biosystems) and $\Delta \mathrm{Ct}$ values were calculated after $\beta$-actin normalization. Two to the power of $-\Delta \mathrm{Ct}\left(2^{-\Delta \mathrm{Ct}}\right)$ was used as a final value to be statistically analyzed.

\section{Viability assay}

Viability of the slices was assessed by measuring the ATP content per milligram tissue using a bioluminescence assay kit (Sigma-Aldrich) as previously reported by Hadi et al. [19]. For each sample, three slices were collected separately in $1 \mathrm{~mL}$ sonification optimization (SONOP) solution pH 10.9 containing $70 \%$ ethanol and $2 \mathrm{nM}$ EDTA.
Table 1. Primer sequences

\begin{tabular}{lcr}
\hline Gene & \multicolumn{1}{c}{ Forward } & Reverse \\
\hline$\beta$-actin & ATCGTGCGTGACATCAAAGA & ATGCCACAGGATTCCATACC \\
TGF $\beta$ & AGGGCTACCATGCCAACTTC & GTTGGACAACTGCTCCACCT \\
IL13R $\alpha 2$ & TGAAAGTGAAGACCTATGCTTT & GACAAACTGGTACTATGAAAAT \\
Col1 $\alpha 1$ & TGACTGGAAGAGCGGAGAGT & ATCCATCGGTCATGCTCTCT \\
$\alpha$ SMA & ACTACTGCCGAGCGTGAGAT & CCAATGAAAGATGGCTGGAA \\
HSP47 & AGGTCACCAAGGATGTGGAG & CAGCTTCTCCTTCTCGTCGT \\
PAI1 & GCCAGATTTATCATCAATGACTGGG & GGAGAGGTGCACATCTTTCTCAAAG \\
FN1 & CGGAGAGAGTGCCCCTACTA & CGATATTGGTGAATCGCAGA \\
\hline
\end{tabular}




\section{Cellular Physiology Cell Physiol Biochem 2022;56:28-38 \\ \begin{tabular}{ll|l} 
and Biochemistry & $\begin{array}{l}\text { DOl: 10.33594/000000492 } \\
\text { Published online: 22 January } 2022\end{array}$ & $\begin{array}{l}\text { O } 2022 \text { The Author(s). Published by } \\
\text { Cell Physiol Biochem Press GmbH\&Co. KG }\end{array}$ \\
\cline { 2 - 3 }
\end{tabular} \\ Adhyatmika et al.: Liver OPG is Induced by IL13}

\section{Statistics}

All statistics were performed using GraphPad Prism 8. As datasets were all $\mathrm{n}<8$, nonparametric tests were used. When comparing 2 groups a Mann Whitney U or Wilcoxon test was used depending on the data being paired or not. When comparing multiple groups, a Friedman or Kruskall-Wallis with Dunn's correction was used. Data are presented as min-to-max box-and-whisker plots with individual data points. For the time course experiment using 3T3 fibroblasts, the areas under the curve from 0.5-12 hours and 12-36 hours were calculated and these were compared between groups. Data in this experiment are presented a median + the interquartile range. For all experiments, $\mathrm{p}<0.05$ was considered significant.

\section{Results}

\section{IL13 induces fibroblast and hepatic OPG production}

To study possible factors that can induce OPG production by fibroblasts, we treated 3T3 fibroblasts with several cytokines associated with fibrosis. In this study we used a major pro-inflammatory and profibrotic cytokine IL1 $\beta$, and pro-fibrotic cytokines IL13 and PDGF-BB with TGF $\beta$ as our positive control as we have shown higher OPG expression with TGF $\beta$ in our previous study [6]. In addition to TGF $\beta$, only IL13 resulted in higher OPG production as compared to control (Fig. 1A). To confirm that IL13 can have a similar effect in liver tissue, we treated murine precision-cut liver slices with IL13 using TGF $\beta$ again as a positive control. We have previously shown in multiple publications that TGF $\beta$ induces robust fibrotic responses in liver slices of fibrosis-associated markers col1 $\alpha 1$, HSP47, FN1, $\alpha S M A$, and PAI 1 on a protein level which tracked well with similar changes on the RNA level $[20,21]$. Similar to treatment with TGF $\beta$, treatment IL13 also resulted in significantly higher OPG release from liver tissue as compared to control (Fig. 1B). This higher OPG release in slices was accompanied by near-significant higher OPG mRNA expression and significant

Fig. 1. IL13 induces OPG release. When $3 \mathrm{~T} 3$ fibroblasts were treated with IL1 $\beta$, IL13, PDGFBB, or TGF $\beta 1$ (positive control) for 24 hours of incubation, only IL13 and TGF $\beta 1$ treatment resulted in significantly higher OPG release as compared to control (A). Murine precisioncut liver slices also released significantly more OPG in culture medium after 48 hours of incubation with IL13 as compared to control, just like positive control TGF $\beta 1$ (B). IL13 incubation also resulted in (near)significant higher expression of the fibrosis-associated genes OPG, Col1 $\alpha 1$, HSP47, and FN1, though not of $\alpha$ SMA and PAI1 (C). In experiments containing multiple groups, treated groups were compared with the control using a Friedman test with Dunn's correction. In experiments containing two groups, these were compared using a Wilcoxon test. $\mathrm{p}<0.05$ was considered significant.

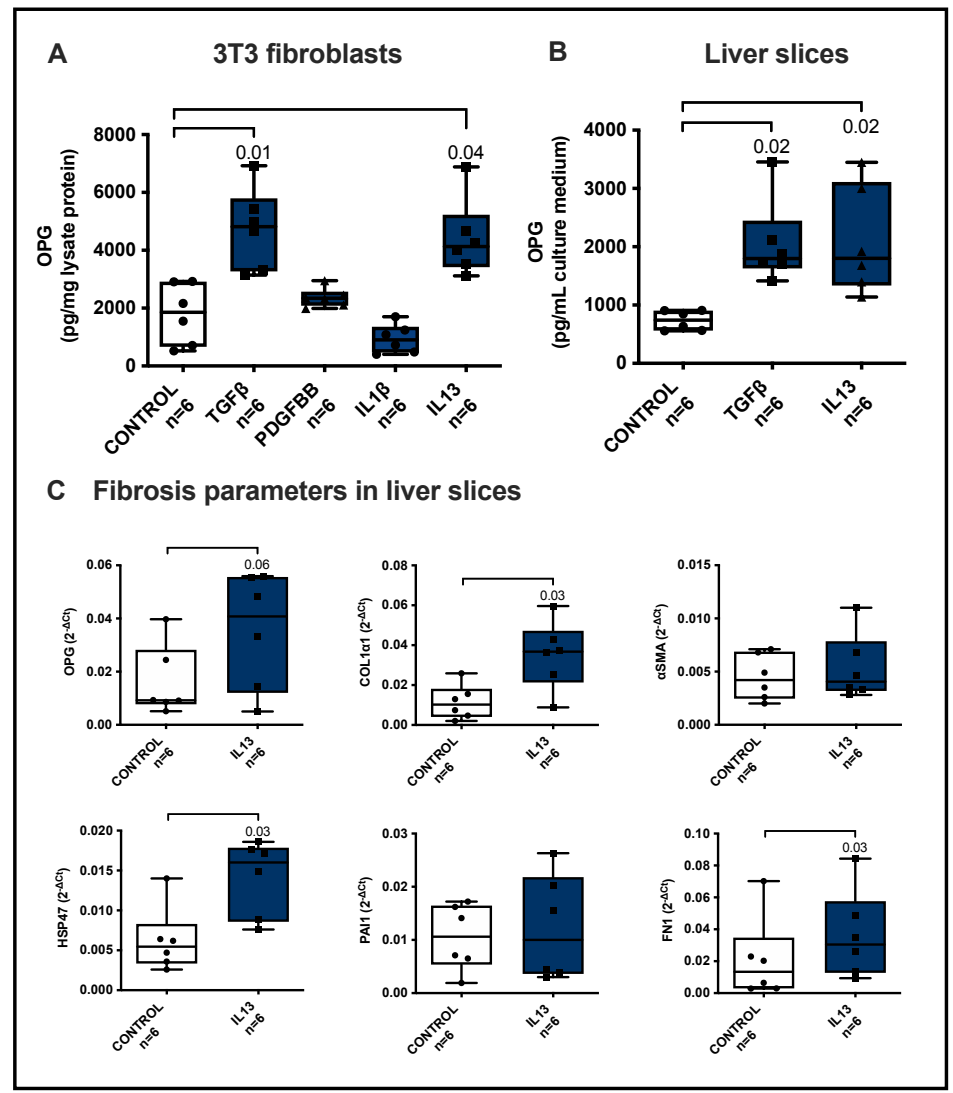


higher expression of fibrosis-associated genes col1 $\alpha 1$, HSP47, and FN1, but not $\alpha$ SMA and PAI1 (Fig. 1C), suggesting IL13 is less fibrogenic than TGF $\beta$. None of the treatments affected the viability of the slices (Supplementary Fig. S1 - for all supplementary material see www. cellphysiolbiochem.com).

\section{IL13 induces OPG production at a slower rate than TGF $\beta$}

To check whether induction of OPG production followed similar kinetics between TGF $\beta$ and IL13, we followed OPG release in time in culture medium of 3T3 fibroblasts after stimulation with TGF $\beta$ and IL13. We found that after 36 hours of incubation IL13 and TGF $\beta$ both induced a similar release in OPG although the induction by TGF $\beta$ occurred somewhat faster. When comparing the area under the curve between stimulated cells and untreated control cells in the first 12 hours, we found a significant increase in OPG release by TGF $\beta$, while IL13 was not significantly different from control. In the time interval from 12 to 36 hours both TGF $\beta$ and IL13 significantly induced OPG release as compared to control (Fig. 2).

\section{IL13 induces hepatic OPG induction through TGF $\beta$}

We hypothesized that TGF $\beta$ may be involved in the higher hepatic OPG production by mouse liver tissue after IL13 treatment as IL13 has been shown to induce TGF $\beta 1$ expression [22]. We therefore assessed TGF $\beta 1$ mRNA expression in liver slices after incubation with IL13 and we found a trend towards higher TGF $\beta 1$ mRNA expression after IL13 treatment compared to untreated control slices (Fig. 3a). To confirm that TGF $\beta$ is indeed involved in the IL13 effect on OPG induction, we also incubated liver slices with galunisertib, a TGF $\beta 1$ receptor inhibitor, together with IL13. We found that with galunisertib cotreatment, IL13 treatment did not result in higher OPG release from liver tissue anymore (Fig. 3b). None of the treatments affected the viability of the slices (Supplementary Fig. S1).

Fig. 2. IL13 induces OPG at a slower rate than TGF $\beta$. 3T3 cells were incubated with TGF $\beta$ or IL13 and OPG release in medium was measured at several time points up to 36 hours. TGF $\beta$ was shown to significantly upregulate OPG release already in the first 12 hours as compared to control, whereas IL13 needed more time for a similar effect. To compare the treated groups with the control condition, the area under the curve from 0.5-12 hrs and 12-36 hrs was calculated and these were compared between treated groups and control using a Friedman

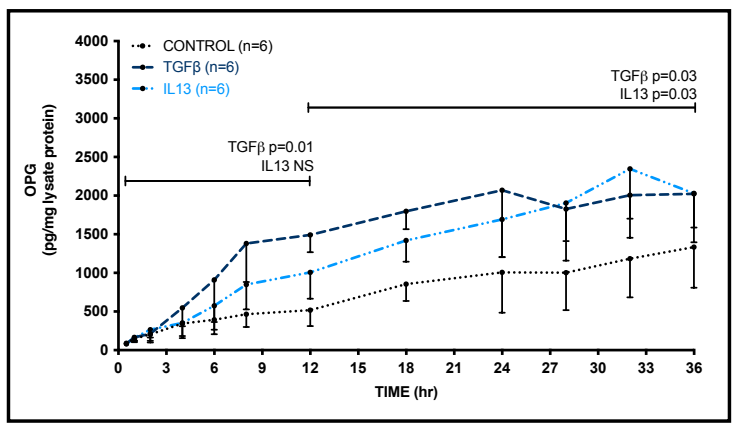
test with Dunn's correction. $\mathrm{p}<0.05$ was considered significant. Data in this experiment are presented a median \pm the interquartile range.

Fig. 3. IL13 induces OPG through TGF $\beta 1$. When mouse liver slices were treated with IL13, we found a trend towards more TGF $\beta 1$ mRNA expression. Groups were compared with a Wilcoxon test, $\mathrm{p}<0.05$ was considered significant (A). Moreover, when IL13 was given together with galunisertib (Galu), a TGFß1-receptor inhibitor, the IL13-induced higher OPG release was not found anymore. Treated groups were compared with the control using a Friedman test with Dunn's correction. $\mathrm{p}<0.05$ was considered significant (B).

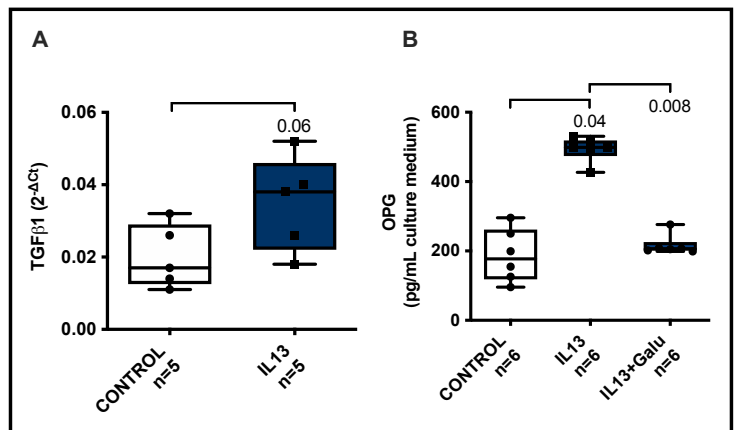


STAT6 is involved in IL13-induced release of OPG

IL13 has been reported to signal through 2 receptors: receptor IL13R $\alpha 1$ and IL13R $\alpha 2$ [23]. The downstream activation pathway of IL13R $\alpha 1$ is via transcription factor STAT6 [24]. To study whether the activation of IL13R $\alpha 1$ and subsequently STAT6 is involved in the IL13induced release of OPG, we treated liver slices of STAT6-deficient mouse with IL13 or TGF $\beta$ and measured OPG released in medium. We found that IL13 failed to induce OPG release by liver slices of STAT6-deficient mice as compared to untreated controls, whereas TGF $\beta$ could still induce OPG release as we found before in wildtype mice (Fig. 4a). To confirm our finding, we used AS1517499, a chemical compound blocking STAT6 activity, in our wild-type mouse liver slices [25] and similarly found that IL13 did not induce OPG release anymore when slices were co-incubated with this inhibitor as compared to slices only treated with IL13 (Fig. 4b). None of the treatments affected the viability of the slices (Supplementary Fig. S1).

\section{IL13 receptor $\alpha 2$ is also involved in IL13-induced OPG release}

Fichtner-Feigl et al. reported that IL13R $\alpha 2$ is involved in induction of TGF $\beta$ expression and fibrosis through transcription factor AP1 [26]. However, in homeostatic conditions, the expression of this receptor is low [27], while activation of IL13R $\alpha 1$ and subsequently STAT6 can induce IL13R $\alpha 2$ expression [28]. In order to check whether these findings are also relevant in our system, we assessed IL13R $\alpha 2$ mRNA expression in liver slices upon IL13 treatment. We found that IL13R $\alpha 2$ mRNA expression level was significantly higher upon IL13 treatment as compared to untreated controls (Fig. 5a). We then used T5224, a chemical inhibitor of AP1 [29] to study whether AP1 in involved in IL13-induced OPG release and we found that indeed chemical inhibition of AP1 completely abolished the IL13-induced release of OPG (Fig. 5b). None of the treatments affected the viability of the slices (Supplementary Fig. S1).

Fig. 4. STAT6 is involved in IL13-induced release of OPG. When liver slices of the STAT6 knock out (KO) mice were incubated for 24 hours with IL13 or TGF $\beta 1$, IL13 failed to induce OPG release, while the TGF $\beta 1$-induced release was not affected by the deficiency in STAT6. Groups were compared using a Friedman test with Dunn's correction, $\mathrm{p}<0.05$ was considered significant (A). IL13-induced OPG release in wild type liver slices could also be blocked with AS1517499, an inhibitor of STAT6 activity. Treated groups were compared with the control using a Friedman test with Dunn's correction. $\mathrm{p}<0.05$ was considered significant (B).

Fig. 5. IL13 receptor $\alpha 2$ is also involved in IL13induced OPG release. Mouse liver slices treated with IL13 had higher IL13R $\alpha 2$ mRNA expression as compared to untreated controls. Groups were compared using a Wilcoxon test, $\mathrm{p}<0.05$ was considered significant (A). Mouse liver slices cotreated with IL13 and T5224, an AP1 inhibitor, did not show higher OPG release as compared to IL13 treatment alone. Treated groups were compared with the control using a Friedman test with Dunn's correction. $\mathrm{p}<0.05$ was considered significant (B).
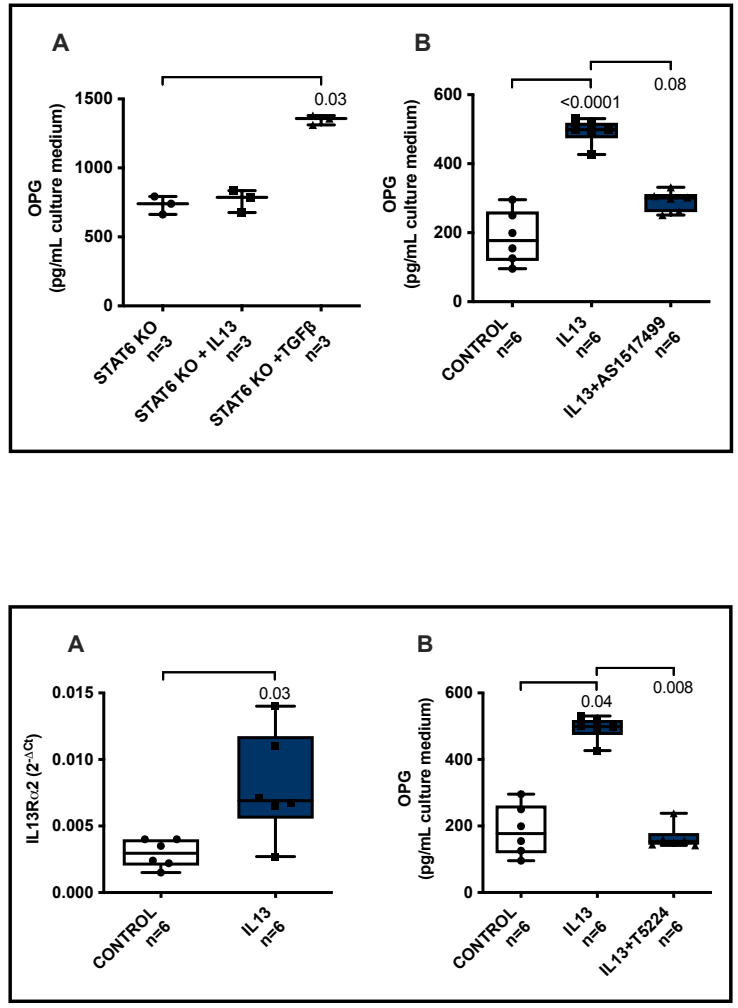


\section{Discussion}

We have previously shown higher OPG expression in fibrotic/cirrhotic conditions and that TGF $\beta$ can induce this hepatic OPG production [6]. Moreover, OPG in its turn was shown to induce TGF $\beta$ expression, contributing to a feed-forward loop. This study now shows that in addition to TGF $\beta$, also the fibrosis-associated cytokine IL13, known to induce collagen expression and promote liver fibrosis via stat- 6 signaling $[30,31]$, can induce OPG expression and release by murine liver tissue. Interestingly, this IL13-induced OPG production is completely dependent on TGF $\beta$ through a pathway involving IL13R $\alpha 1$ /STAT6 and IL13R $\alpha 2 / A P 1$. The strength of this study is that we used precision-cut liver tissue slices, instead of cultures of individual cells or cell lines, making our results more relevant for in vivo situations.

In our previous studies we identified fibroblasts as the main source of OPG production in liver during fibrogenesis and after TGF $\beta$ exposure. Little is known about the regulation of OPG production in these cells and in liver tissue itself. We therefore investigated the effect on OPG production of other cytokines/growth factors involved in fibrogenesis. For this we chose IL13 and PDGF-BB as these were identified as important fibrogenic regulators of fibroblasts and therefore fibrosis, and are being investigated as potential targets of antifibrotic drugs [32$34]$. We also chose IL1 $\beta$ because this key cytokine is involved in chronic liver inflammation and subsequent development of fibrosis [35]. Our results showed no influence of IL1 $\beta$ on the production of OPG by fibroblasts. This finding suggests that OPG is mostly produced in connection to fibrogenesis and not during inflammation that may precede the development of fibrosis. Furthermore, PDGF-BB did not induce OPG production in fibroblasts either. PDGF-BB is the mitogenic agent for fibroblasts and triggers proliferation and migration of these cells. The pathways leading to stimulation of proliferation by PDGF-BB are apparently not linked to stimulation of OPG production.

IL13 stimulation on the other hand, did lead to higher production of OPG in fibroblasts. This effect was confirmed using precision-cut liver slices of murine livers and this experiment also showed us that the higher OPG expression and production after IL13 stimulation was accompanied by higher expression of fibrosis-associated markers Col1 $\alpha 1$, HSP47, and Fn2. These profibrotic results of IL13 are in line with previously published results by Sugimoto et al. [36] and Gieseck et al. [32], who showed that IL13 can induce collagen production and fibrogenesis in hepatic stellate cells and liver tissue respectively. Induction of fibrogenesis by IL13 has been suggested to occur via upregulation of TGF $\beta 1$ via IL13R $\alpha 1$ and IL13R $\alpha 2$ signaling [26, 36-38], although other studies have suggested that IL13 can also induce fibrosis independently from TGF $\beta$ [39]. Our data show that the IL13-induced production of OPG is completely dependent on TGF $\beta 1$, as inhibition of TGF $\beta 1$-signaling with galunisertib completely abrogated the effect of IL13 on OPG production. We also confirmed that both IL13 receptors are involved in this TGF $\beta 1$-mediated OPG production in liver tissue [26, 3638]. Blocking or the absence of STAT6 fully blocked IL13-induced OPG production by liver tissue, showing that IL13R $\alpha 1$-signaling through STAT6 is necessary to upregulate TGF $\beta 1$ and subsequently OPG. Furthermore, we showed that IL13 stimulation leads to higher expression of IL13R $\alpha 2$ in liver tissue and that blocking signaling of this receptor with an AP1 inhibitor also completely abrogated IL13-induced OPG production in liver tissue. A scheme explaining these main findings is depicted in Fig. 6.

The signaling through both IL13 receptors and the need for TGF $\beta 1$ upregulation before OPG can be produced, probably also explains why IL13-induced OPG production was lagging in comparison to TGF $\beta 1$-induced OPG production. In 36 hours, both cytokines can induce production of similar levels of OPG, but we found that TGF $\beta 1$ can achieve these levels faster. IL13R $\alpha 2$ is expressed at low levels in normal liver tissue and can therefore not induce TGF $\beta 1$ expression immediately when liver tissue is exposed to IL13. The fact that IL13 first needs to upregulate IL13R $\alpha 2$ through IL13R $\alpha 1$ and STAT6 to be able to stimulate TGF $\beta 1$ expression probably accounts for the delayed production of OPG after IL13 stimulation. 


\section{Cellular Physiology Cell Physiol Biochem 2022;56:28-38 \begin{tabular}{ll|l} 
and Bol: 10.33594/000000492 & O 2022 The Author(s). Published by \\
Cell Physiol Biochem Press GmbH\&Co. KG
\end{tabular}

Fig. 6. IL13 induces liver OPG production via activation of both IL13 receptors and subsequent induction of TGF $\beta 1$. A schematic overview of IL13-induced OPG production based on the results presented in this study. (1) IL13 binds to receptor $\alpha 1$ followed by activation of this receptor triggering (2) STAT6 activation resulting in (3) the increased expression of IL13 receptor $\alpha 2$, which is initially expressed at low levels. (4) IL13 then binds to receptor $\alpha 2$, triggering (5) activation of transcription factor AP1, which induces (6) expression of TGF $\beta 1$. Finally, as we have reported in our previous study [6], TGF $\beta 1$ can induce OPG protein production by the liver (7).

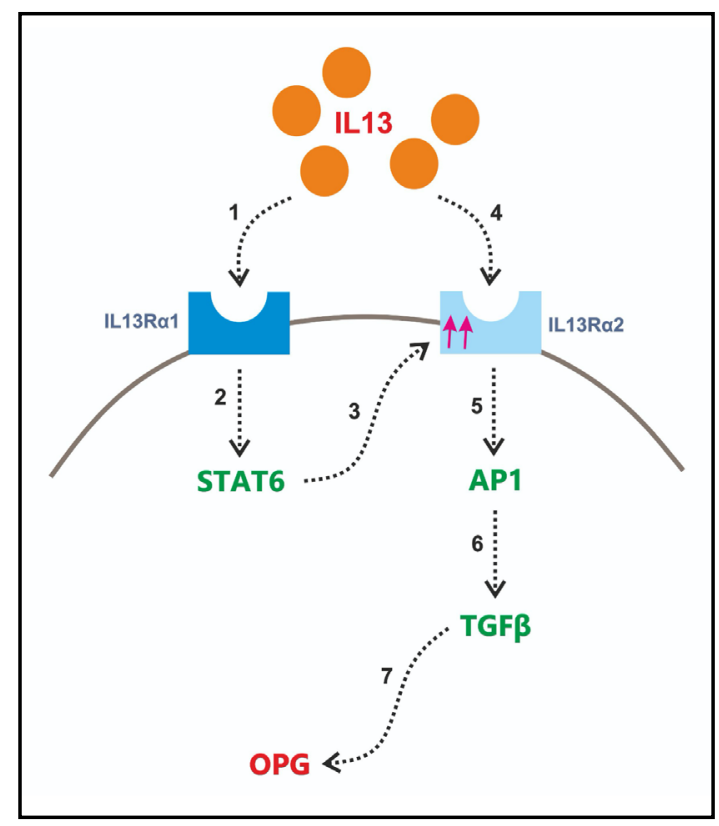

Our results point at an interesting feed-forward mechanism in liver tissue involving TGF $\beta 1$ as a central player, with IL13 prolonging profibrogenic TGF $\beta$ signaling via induction of the TGF $\beta$ inducer OPG. Both TGF $\beta 1$ and IL13 can induce OPG and OPG can induce expression of TGF $\beta 1$ again [6]. In most cases, liver tissue damage will result in normal repair and restoration of fully functional liver tissue. Therefore, there must also be brakes in this process to prevent that any type of damage will always end in fibrosis. Our current studies focus on several microRNAs that are induced by TGF $\beta 1$ and that may serve as the brakes in this feed-forward loop. Another interesting aspect of our findings is the possibility of using OPG as a target for therapy. Both TGF $\beta 1$ and IL13 are targets for inhibition of fibrogenesis that are currently being explored in clinical trials [39-43]. As OPG is linking both pathways it seems to be another promising target for therapy.

\section{Conclusion}

We have shown that IL13 induces OPG release by liver tissue through a TGF $\beta$-dependent pathway involving both the $\alpha 1$ and the $\alpha 2$ receptor of IL13 and transcription factors STAT6 and AP1. OPG may therefore be a novel target for the treatment liver fibrosis as it is mechanistically linked to two important regulators of fibrosis in liver, namely IL13 and TGFß1.

\section{Acknowledgements}

\section{Author Contributions}

Conceptualization, A.A., L.B., and B.N.M., data curation, A.A., K.S.S.P., E.G., K.A.M., C.R.-S., and B.N.M., formal analysis, A.A., L.B., and B.N.M., funding acquisition, P.O., and B.N.M., investigation, A.A., L.B., and B.N.M., methodology, A.A., K.S.S.P., L.B., C.R.-S., D.S., P.O., and B.N.M., project administration, B.N.M., resources, B.N.M., software, B.N.M., supervision, L.B., P.O., and B.N.M., validation, L.B. and B.N.M., visualization, A.A., L.B., and B.N.M., writingoriginal draft, A.A., K.S.S.P. and B.N.M., writing-review and editing, K.A.M., C.R.-S., D.S., L.B., P.O., and B.N.M. All authors have read and agreed to the published version of the manuscript. 


\section{Cellular Physiology Cell Physiol Biochem 2022;56:28-38

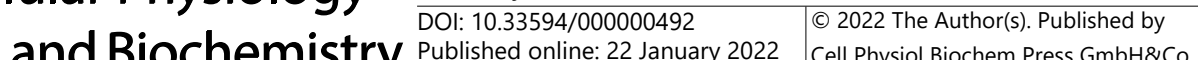 \\ Published online: 22 January 2022 Cell Physiol Biochem Press GmbH\&Co. KG \\ Adhyatmika et al.: Liver OPG is Induced by IL13}

\section{Funding Sources}

A.A. received scholarship from LPDP (The Indonesian Endowment Funds for Education, Ministry of Finance, Republic of Indonesia) and K.S.S.P. from DIKTI (The Ministry of Higher Education, Republic of Indonesia) to undergo their Ph.D. education in the Groningen Research Institute of Pharmacy, University of Groningen, The Netherlands. DS received project-related support from EU Horizon 2020 projects under grant agreements nr. 634413 (EPoS, European Project on Steatohepatitis).

\section{Statement of Ethics}

The use of C57BL/ 6 mice in this study was approved by the Institutional Animal Care and Use Committee of the University of Groningen (DEC 6416 AA) and the use of STAT6(-/-) mice by the Institutional Animal Care and Use Committee of the Government of Rhineland Palatinate under the reference number 2317707/G12-1-007.

\section{Disclosure Statement}

The authors have no conflicts of interest to declare.

\section{References}

1 Friedman SL: Liver fibrosis -- from bench to bedside. J Hepatol 2003;38:S38-S53.

2 Bataller R, Brenner DA: Liver fibrosis. J Clin Invest 2005;115:209-218.

3 Ismail MH, Pinzani M: Reversal of liver fibrosis. Saudi J Gastroenterol 2009;15:72-79.

4 Xu F, Liu C, Zhou D, Zhang L: TGF-beta/SMAD Pathway and Its Regulation in Hepatic Fibrosis. J Histochem Cytochem 2016;64:157-167.

5 Fabregat I, Moreno-Caceres J, Sanchez A, Dooley S, Dewidar B, Giannelli G, Ten Dijke P, Consortium I-L: TGFbeta signalling and liver disease. FEBS J 2016;283:2219-2232.

6 Adhyatmika A, Beljaars L, Putri KSS, Habibie H, Boorsma CE, Reker-Smit C, Luangmonkong T, Guney B, Haak A, Mangnus KA, Post E, Poelstra K, Ravnskjaer K, Olinga P, Melgert BN: Osteoprotegerin is more than a possible serum marker in liver fibrosis: A study into its function in human and murine liver. Pharmaceutics 2020;12:1-21.

7 Garcia-Valdecasas-Campelo E, Gonzalez-Reimers E, Santolaria-Fernandez F, De la Vega-Prieto MJ, MilenaAbril A, Sanchez-Perez MJ, Martinez-Riera A, Gomez-Rodriguez Mde L: Serum osteoprotegerin and RANKL levels in chronic alcoholic liver disease. Alcohol Alcohol 2006;41:261-266.

8 Bosselut N, Taibi L, Guechot J, Zarski JP, Sturm N, Gelineau MC, Poggi B, Thoret S, Lasnier E, Baudin B, Housset C, Vaubourdolle M, Group AHF: Including osteoprotegerin and collagen IV in a score-based blood test for liver fibrosis increases diagnostic accuracy. Clin Chim Acta 2013;415:63-68.

9 Prystupa A, Dabrowska A, Sak JJ, Tarach J, Torun-Jurkowska A, Lachowska-Kotowska P, Dzida G: Concentrations of fetuin-A, osteoprotegerin and alpha-Klotho in patients with alcoholic liver cirrhosis. Exp Ther Med 2016;12:3464-3470.

10 Monegal A, Navasa M, Peris P, Alvarez L, Pons F, Rodes J, Guanabens N: Serum osteoprotegerin and its ligand in cirrhotic patients referred for orthotopic liver transplantation: relationship with metabolic bone disease. Liver Int 2007;27:492-497.

11 Fabrega E, Orive A, Garcia-Suarez C, Garcia-Unzueta M, Antonio Amado J, Pons-Romero F: Osteoprotegerin and RANKL in alcoholic liver cirrhosis. Liver Int 2005;25:305-310.

12 Szalay F, Hegedus D, Lakatos PL, Tornai I, Bajnok E, Dunkel K, Lakatos P: High serum osteoprotegerin and low RANKL in primary biliary cirrhosis. J Hepatol 2003;38:395-400.

13 Moschen AR, Kaser A, Stadlmann S, Millonig G, Kaser S, Muhllechner P, Habior A, Graziadei I, Vogel W, Tilg $\mathrm{H}$ : The RANKL/OPG system and bone mineral density in patients with chronic liver disease. J Hepatol 2005;43:973-983.

14 Boyce BF, Xing L: Biology of RANK, RANKL, and osteoprotegerin. Arthritis Res Ther 2007;9:S1. 


\section{Cellular Physiology Cell Physiol Biochem 2022;56:28-38 \begin{tabular}{ll|l} 
and Biochemistry $10.33594 / 000000492$ & $\begin{array}{l}\text { Dublished online: } 22 \text { January } 2022 \\
\text { Pull } 2022 \text { The Author(s). Published by } \\
\text { Cell Physiol Biochem Press GmbH\&Co. KG }\end{array}$ \\
\hline
\end{tabular}}

Adhyatmika et al.: Liver OPG is Induced by IL13

15 Harper E, Forde H, Davenport C, Rochfort KD, Smith D, Cummins PM: Vascular calcification in type-2 diabetes and cardiovascular disease: Integrative roles for OPG, RANKL and TRAIL. Vascul Pharmacol 2016;82:30-40.

16 Wallace K, Burt AD, Wright MC: Liver fibrosis. Biochem J 2008;411:1-18.

17 Akimoto T, Numata F, Tamura M, Takata Y, Higashida N, Takashi T, Takeda K, Akira S: Abrogation of bronchial eosinophilic inflammation and airway hyperreactivity in signal transducers and activators of transcription (STAT)6-deficient mice. J Exp Med 1998;187:1537-1542.

18 de Graaf IA, Olinga P, de Jager MH, Merema MT, de Kanter R, van de Kerkhof EG, Groothuis GM: Preparation and incubation of precision-cut liver and intestinal slices for application in drug metabolism and toxicity studies. Nat Protoc 2010;5:1540-1551.

19 Hadi M, Chen Y, Starokozhko V, Merema MT, Groothuis GM: Mouse precision-cut liver slices as an ex vivo model to study idiosyncratic drug-induced liver injury. Chem Res Toxicol 2012;25:1938-1947.

20 Bigaeva E, Gore E, Simon E, Zwick M, Oldenburger A, de Jong KP, Hofker HS, Schleputz M, Nicklin P, Boersema M, Rippmann JF, Olinga P: Transcriptomic characterization of culture-associated changes in murine and human precision-cut tissue slices. Arch Toxicol 2019;93:3549-3583.

21 Bigaeva E, Gore E, Mutsaers HAM, Oosterhuis D, Kim YO, Schuppan D, Bank RA, Boersema M, Olinga P: Exploring organ-specific features of fibrogenesis using murine precision-cut tissue slices. Biochim Biophys Acta Mol Basis Dis 2020;1866:165582.

22 Lee CG, Homer RJ, Zhu Z, Lanone S, Wang X, Koteliansky V, Shipley JM, Gotwals P, Noble P, Chen Q, Senior RM, Elias JA: Interleukin-13 induces tissue fibrosis by selectively stimulating and activating transforming growth factor beta(1). J Exp Med 2001;194:809-821.

23 Chomarat P, Banchereau J: Interleukin-4 and interleukin-13: their similarities and discrepancies. Int Rev Immunol 1998;17:1-52.

24 Murata T, Husain SR, Mohri H, Puri RK: Two different IL-13 receptor chains are expressed in normal human skin fibroblasts, and IL-4 and IL-13 mediate signal transduction through a common pathway. Int Immunol 1998;10:1103-1110.

25 Chiba Y, Todoroki M, Nishida Y, Tanabe M, Misawa M: A novel STAT6 inhibitor AS1517499 ameliorates antigen-induced bronchial hypercontractility in mice. Am J Respir Cell Mol Biol 2009;41:516-524.

26 Fichtner-Feigl S, Strober W, Kawakami K, Puri RK, Kitani A: IL-13 signaling through the IL-13alpha2 receptor is involved in induction of TGF-beta1 production and fibrosis. Nat Med 2006;12:99-106.

27 Daines MO, Tabata Y, Walker BA, Chen W, Warrier MR, Basu S, Hershey GK: Level of expression of IL-13R alpha 2 impacts receptor distribution and IL-13 signaling. J Immunol 2006;176:7495-7501.

28 David M, Ford D, Bertoglio J, Maizel AL, Pierre J: Induction of the IL-13 receptor alpha2-chain by IL-4 and IL-13 in human keratinocytes: involvement of STAT6, ERK and p38 MAPK pathways. Oncogene 2001;20:6660-6668.

29 Aikawa Y, Morimoto K, Yamamoto T, Chaki H, Hashiramoto A, Narita H, Hirono S, Shiozawa S: Treatment of arthritis with a selective inhibitor of c-Fos/activator protein-1. Nat Biotechnol 2008;26:817-823.

30 Firszt R, Francisco D, Church TD, Thomas JM, Ingram JL, Kraft M: Interleukin-13 induces collagen type-1 expression through matrix metalloproteinase- 2 and transforming growth factor-beta1 in airway fibroblasts in asthma. Eur Respir J 2014;43:464-473.

31 Weng SY, Wang X, Vijayan S, Tang Y, Kim YO, Padberg K, Regen T, Molokanova O, Chen T, Bopp T, Schild H, Brombacher F, Crosby JR, McCaleb ML, Waisman A, Bockamp E, Schuppan D: IL-4 Receptor Alpha Signaling through Macrophages Differentially Regulates Liver Fibrosis Progression and Reversal. EBioMedicine 2018;29:92-103.

32 Gieseck RL, 3rd, Ramalingam TR, Hart KM, Vannella KM, Cantu DA, Lu WY, Ferreira-Gonzalez S, Forbes SJ, Vallier L, Wynn TA: Interleukin-13 Activates Distinct Cellular Pathways Leading to Ductular Reaction, Steatosis, and Fibrosis. Immunity 2016;45:145-158.

33 Wynn TA: Cellular and molecular mechanisms of fibrosis. J Pathol 2008;214:199-210.

34 Bonner JC: Regulation of PDGF and its receptors in fibrotic diseases. Cytokine Growth Factor Rev 2004;15:255-273.

35 Szabo G, Csak T: Inflammasomes in liver diseases. J Hepatol 2012;57:642-654.

36 Sugimoto R, Enjoji M, Nakamuta M, Ohta S, Kohjima M, Fukushima M, Kuniyoshi M, Arimura E, Morizono S, Kotoh K, Nawata H: Effect of IL-4 and IL-13 on collagen production in cultured LI90 human hepatic stellate cells. Liver Int 2005;25:420-428. 


\section{Cellular Physiology and Biochemistry}

37 Shimamura T, Fujisawa T, Husain SR, Kioi M, Nakajima A, Puri RK: Novel role of IL-13 in fibrosis induced by nonalcoholic steatohepatitis and its amelioration by IL-13R-directed cytotoxin in a rat model. J Immunol 2008;181:4656-4665.

38 Lin J, Lu F, Zheng W, Xu S, Tai D, Yu H, Huang Z: Assessment of liver steatosis and fibrosis in rats using integrated coherent anti-Stokes Raman scattering and multiphoton imaging technique. J Biomed Opt 2011;16:116024.

39 Korenblat P, Kerwin E, Leshchenko I, Yen K, Holweg CTJ, Anzures-Cabrera J, Martin C, Putnam WS, Governale L, Olsson J, Matthews JG: Efficacy and safety of lebrikizumab in adult patients with mild-tomoderate asthma not receiving inhaled corticosteroids. Respir Med 2018;134:143-149.

40 Akhurst RJ, Hata A: Targeting the TGFbeta signalling pathway in disease. Nat Rev Drug Discov 2012;11:790811.

41 Schuppan D, Kim YO: Evolving therapies for liver fibrosis. J Clin Invest 2013;123:1887-1901.

42 Guttman-Yassky E, Blauvelt A, Eichenfield LF, Paller AS, Armstrong AW, Drew J, Gopalan R, Simpson EL: Efficacy and Safety of Lebrikizumab, a High-Affinity Interleukin 13 Inhibitor, in Adults With Moderate to Severe Atopic Dermatitis: A Phase 2b Randomized Clinical Trial. JAMA Dermatol 2020;156:411-420.

43 Simpson EL, Flohr C, Eichenfield LF, Bieber T, Sofen H, Taieb A, Owen R, Putnam W, Castro M, DeBusk K, Lin CY, Voulgari A, Yen K, Omachi TA: Efficacy and safety of lebrikizumab (an anti-IL-13 monoclonal antibody) in adults with moderate-to-severe atopic dermatitis inadequately controlled by topical corticosteroids: A randomized, placebo-controlled phase II trial (TREBLE). J Am Acad Dermatol 2018;78:863-871.e11. 